\title{
Lipids of Candida albicans: subcellular distribution and biosynthesis
}

\author{
N. MAGo and G. K. KHULLER* \\ Department of Biochemistry, Postgraduate Institute of Medical Education and Research, Chandigarh-160012, India
}

(Received 11 October 1989; revised 13 December 1989; accepted 20 February 1990)

\begin{abstract}
Lipids constituted around $5 \%$ of the dry weight in Candida albicans 3153, while sterols and phospholipids accounted for $1.2 \%$ and $1.1 \%$ respectively. Phospholipids were mainly localized in the microsomal fraction; phosphatidylserine (PS), phosphatidylcholine (PC), phosphatidylethanolamine (PE) and phosphatidylinositol (PI) were the major phospholipids. Incorporation studies with $\left[{ }^{14} \mathrm{C}\right]$ acetate and $\left[\mathrm{I}^{32} \mathrm{P} \mid\right.$ orthophosphoric acid demonstrated that PS was synthesized at the highest rate followed by PC, PE and PI. There was little difference in either the content or the rate of biosynthesis of PC, PE and PI. Incorporation of labelled serine, ethanolamine and choline revealed serine to be a precursor for PC, PE and PS, ethanolamine for PC and PE, and choline for PC biosynthesis only.
\end{abstract}

\section{Introduction}

Lipids of micro-organisms are important not only due to their interaction with antimicrobial drugs (Fryberg et al., 1975; Yamaguchi, 1977), but also because of their response to changes in the growth medium. For Candida albicans, there are reports on the lipid composition of the plasma membrane and cell wall (Marriott, 1975), variation in lipid composition associated with dimorphism (Ghannoum et al., 1986), and the effect of antifungal agents on lipids (Singh et al., 1979). Total lipid content ranges from $7 \%$ to $32 \%$ in various species of Candida (Kaneko et al., 1976). Phosphatidylcholine (PC), phosphatidylethanolamine (PE), phosphatidylserine (PS) and phosphatidylinositol (PI) represent the major phospholipids, while triglycerides, free sterols, esterified sterols and free fatty acids are the major neutral lipids (Henry et al., 1981; Kaneko et al., 1976). Although C. albicans lipids have been studied in detail, information on lipid biosynthesis is meagre and variation in lipid content among different strains has not been studied. The study of lipid composition of different subcellular organelles and their synthesis should help to determine their functional capabilities, as phospholipids are the structural components of biomembranes. Therefore, we have examined the composition and biosynthesis of lipids in C. albicans using various precursors.

\footnotetext{
Abbreviations: CL, cardiolipin; LPC, lysophosphatidylcholine; PC, phosphatidylcholine; PE, phosphatidylethanolamine; PI, phosphatidylinositol; PS, phosphatidylserine.
}

\section{Methods}

Materials. $\left[1-{ }^{3} \mathrm{H}\right]$ Ethanolamine (specific activity $8.8 \mathrm{mCi} \mathrm{mmol}^{-1}$; $325.6 \mathrm{MBq} \mathrm{mmol}^{-1}$ ) was obtained from Amersham. [methyl $\left.{ }^{14} \mathrm{C}\right] \mathrm{Cho}-$ line chloride (specific activity $5 \mathrm{mCi} \mathrm{mmol}^{-1} ; 185 \mathrm{MBq} \mathrm{mmol}^{-1}$ ), [U.-14 C]serine (specific activity $173 \mathrm{mCi} \mathrm{mmol}^{-1} ; 6401 \mathrm{MBq} \mathrm{mmol}^{-1}$ ), $\left[1-{ }^{14} \mathrm{C}\right]$ acetate (specific activity $60.3 \mathrm{mCi} \mathrm{mmol}^{-1} ; 2231 \mathrm{MBq}$ mmol-1) and [ ${ }^{32}$ P]orthophosphoric acid (carrier-free) were obtained from BARC, Bombay, India.

Organism and growth conditions. C. albicans 3153, obtained from the Mycological Reference Laboratory, Colindale, London, UK, was maintained on Sabouraud's dextrose broth and cultivated in a defined medium containing $0.3 \% \mathrm{KH}_{2} \mathrm{PO}_{4}, 0.3 \% \quad\left(\mathrm{NH}_{4}\right)_{2} \mathrm{SO}_{4}, 0.025 \%$ $\mathrm{MgSO}_{4} .7 \mathrm{H}_{2} \mathrm{O}, 0.025 \% \mathrm{CaCl}_{2} .2 \mathrm{H}_{2} \mathrm{O}, 0.001 \%$ biotin and $0.5 \%$ glucose as carbon source at $37^{\circ} \mathrm{C}$ on a gyrotatory shaker ( 200 r.p.m.). Cells were harvested in the stationary phase (after $24 \mathrm{~h}$ ) for lipid analysis and in the exponential phase (after $16 \mathrm{~h}$ ) for studies of lipid biosynthesis.

Subcellular fractionation of cells. Cells were harvested, washed and sonicated in $0.01 \mathrm{M}$-Tris $/ \mathrm{HCl} \mathrm{pH} 8.0$ containing $250 \mathrm{~mm}$-sucrose in a Branson Sonifier for $30 \mathrm{~min}$ in ice at $60 \mathrm{~W}$. The homogenate was then centrifuged at $5000 \mathrm{~g}$ for $20 \mathrm{~min}$ to remove cell debris. Cell fractionation and characterization was done according to the procedure of Chavant et al. (1980) except that mitochondria and microsomes were isolated by centrifugation at $15000 \mathrm{~g}$ and $105000 \mathrm{~g}$ respectively.

Labelling of lipids. Cells were washed with $0.85 \% \mathrm{NaCl}$ and resuspended in medium (for ${ }^{32} \mathrm{P}$-incorporation experiments, phosphorus-free medium was used) under sterile conditions. Cells were preincubated at $37^{\circ} \mathrm{C}$ for $30 \mathrm{~min}$ with shaking. Precursors $(10 \mu \mathrm{Ci}$ $\left[{ }^{14} \mathrm{C}\right]$ acetate, $4 \mathrm{mCi}\left[{ }^{32} \mathrm{P}\right]$ orthophosphate, $6 \mu \mathrm{Ci}\left[{ }^{14} \mathrm{C}\right]$ serine, $6 \mu \mathrm{Ci}$ $\left[{ }^{3} \mathrm{H}\right]$ ethanolamine or $6 \mu \mathrm{Ci}\left[{ }^{14} \mathrm{C}\right]$ choline chloride per $\mathrm{g}$ of cells) were added to cells suspended in $50 \mathrm{ml}$ medium and at different time intervals $3 \mathrm{ml}$ samples from each culture were transferred into tubes containing $0.5 \mathrm{ml} 1 \mathrm{M}-\mathrm{KCN}$ (Kilburn et al., 1981). The tubes were centrifuged at $2700 \mathrm{~g}$ for $15 \mathrm{~min}$. The cell pellet was recovered and lipids extracted. Radioactivity was counted in Packard Tricarb scintillation counter using a toluene-based scintillation fluid. 
Quantification of lipids. Lipids were extracted by the method of Folch et al. (1957). Phospholipids were quantified by the method of Marinetti (1962), and sterols by the method of Zlatkis et al. (1953), which is specific for ergosterol/cholesterol. Lipids of the subcellular fractions were extracted by the method of Bligh \& Dyer (1959). Individual phospholipids were separated by one-dimensional thinlayer chromatography on silica gel $\mathrm{H}$ plates in chloroform/methanol/7 $\mathrm{M}-\mathrm{NH}_{3}(65: 25: 4$, by vol.). Fatty acid methyl esters of phospholipids (separated from the neutral lipids by thin-layer chromatography) were prepared by transesterification with methanol in the presence of thionyl chloride (Khuller et al., 1981) and were resolved in an AIMILNucon gas chromatogram fitted with a DEGS column at $180^{\circ} \mathrm{C}$ using nitrogen as a carrier gas (flow rate $40 \mathrm{ml} \mathrm{min}^{-1}$ ). Fatty acid methyl esters were identified by comparison of their retention times with those of authentic standards. Fatty acids were quantified by triangulation.

\section{Results and Discussion}

\section{Lipid composition}

The total lipid content of $C$. albicans 3153 was $5 \cdot 15 \pm 0.27 \%$ of the dry weight. Phospholipids and sterols represented $1 \cdot 11 \pm 0.11$ and $1.22 \pm 0.13 \%$ of the dry weight, respectively, and these components were present in equimolar ratio (Table 1). Hitchcock et al. (1986) reported the total lipid content of this strain to be $0.85 \%$, and the ratio of phospholipids to sterols to be $3: 1$. These variations in results are presumably due to differences in growth medium or stage of growth. In earlier studies with different strains of $C$. albicans, total lipid content of $C$. albicans ATCC 10231 was found to vary from 0.3 to $6.3 \%$ of the dry weight, and that of $C$. albicans $1 \mathrm{Ha} 582$ was $13.9 \%$ of the dry weight (Weete, 1980). The group and fatty acid composition of lipids from 62 species and strains of Candida was investigated by Malkhas'ian et al. (1982) but no strict correlation between the composition of lipids and yeast species was found.

Our analysis of individual phospholipids of C. albicans 3153 revealed the presence of $\mathrm{PC}, \mathrm{PE}, \mathrm{PS}, \mathrm{PI}$ and cardiolipin (CL) of which PS constituted the greatest amount and CL the least. Hitchock et al. (1986) and Ghannoum et al. (1986) have also reported PC, PE, PS and PI to be major phospholipids of C. albicans, although in their case PC was present in the largest quantity followed by PE, PS and PI. Since the lipid composition of plasma membranes of C. albicans has been determined earlier (Marriott, 1975), it was of interest to study the lipid composition of two other metabolically active organelles, mitochondria and microsomes, of which little is known. Phospholipid analysis of subcellular fractions revealed that the greatest amounts were present in the microsomal fraction $\left[30 \cdot 11 \pm 5.05 \mathrm{mg}(\mathrm{g} \text { dry } \mathrm{wt})^{-1}\right.$ (mean $\pm \mathrm{SD}, n=4)$ ]. The mitochondrial fraction con-
Table 1. Lipid composition of whole cells of C. albicans 3153

\begin{tabular}{lc}
\hline \hline Lipid fraction & {$\left[\mathrm{mg}(\mathrm{g} \mathrm{dry} \mathrm{wt})^{-1}\right]$} \\
\hline Total lipids* & $51.55 \pm 2.75$ \\
Sterols $\dagger$ & $12.19 \pm 1.30$ \\
Phospholipids $\dagger$ & $11.09 \pm 1.1$ \\
Individual phospholipids* & $1 \cdot 17 \pm 0.14$ \\
PI & $3.90 \pm 0.30$ \\
PS & $1.75 \pm 0.19$ \\
PC & $1.39 \pm 0.02$ \\
PE & $0.84 \pm 0.13$ \\
CL & $1.41 \pm 0.17$ \\
UPL $\ddagger$ & \\
\hline \hline
\end{tabular}

* Values are means $\pm S D$ of five different batches.

+ Values are means \pm SD of eight different batches.

$\ddagger$ UPL, unknown phospholipids.

tained a considerable amount of phospholipids $\left[12.26 \pm 1.91 \mathrm{mg}(\mathrm{g} \mathrm{dry} \mathrm{wt})^{-1}\right]$ while the cytosolic fraction contained only negligible amounts $[0.12 \pm 0.04 \mathrm{mg}$ (g dry wt) $)^{-1}$.

Fatty acid analysis of the phospholipids of whole cells of $C$. albicans revealed that $\mathrm{C}_{16: 0}(24 \%), \mathrm{C}_{18: 1}(15 \%)$, $\mathrm{C}_{18: 2}(32 \%)$ and $\mathrm{C}_{18: 0}(8.6 \%)$ were the main fatty acids while $C_{10: 0}, C_{12: 0}, C_{14: 0}, C_{14: 1}, C_{16: 1}$ and $C_{16: 2}$ were minor ones (each less than $5 \%$ ). These results are in agreement with those of Pierce et al. (1978) and Hitchcock et al. (1986), who reported $\mathrm{C}_{16: 0}, \mathrm{C}_{16: 1}, \mathrm{C}_{18: 1}$ and $C_{18: 2}$ as major fatty acids. Differences between results of the present study and earlier ones (Ghannoum et al., 1986) are probably due to differences in growth phase and composition of the medium. In comparison to whole cells, subcellular fractions contained larger amounts of $\mathrm{C}_{16: 0}(60 \%$ in mitochondria and microsomes and $35 \%$ in cytosol), while the levels of $C_{18: 2}$ were significantly lower $(32 \%$ in whole cells to traces in various fractions) with marginal changes in $\mathrm{C}_{18: 0}$. There was little change in $C_{18: 1}$, while $C_{16: 1}$ increased considerably. Since relative percentage was measured and not the absolute amount, abundance of one fatty acid would decrease the percentage of other fatty acids. The mitochondrial and microsomal fractions had almost the same fatty acid composition while cytosolic fractions contained two extra fatty acids $\left(\mathrm{C}_{14: 0}, \mathrm{C}_{14: 1}\right)$ as major components $\left(20 \%\right.$ and $14 \%$ ) in addition to $\mathrm{C}_{16: 0}, \mathrm{C}_{16: 1}$ and $\mathrm{C}_{18: 1}$ present in mitochondria and microsomes.

\section{Lipid biosynthesis}

Lipid biosynthesis in $C$. albicans was studied with $\left[{ }^{14} \mathrm{C}\right]$ acetate, a general precursor for all lipids, and [32 P]orthophosphoric acid, a specific precursor for 
phospholipids. Incorporation of $\left[{ }^{14} \mathrm{C}\right]$ acetate into total lipids increased for $10 \mathrm{~min}$, but it was only linear for 6 min (Fig. 1a); a similar pattern was exhibited for $\left[{ }^{14} \mathrm{C}\right]$ acetate incorporation into total phospholipids. Incorporation of $\left[{ }^{14} \mathrm{C}\right]$ acetate into individual phospholipids indicated that PS was synthesized at the highest rate while PI, PC and PE had almost the same rate of synthesis. These results differ from those of Ballman \& Chaffin (1979), who found that the sequence of synthesis was $\mathrm{PC}>\mathrm{PE}>\mathrm{PS}$. However, in that case lipid biosynthesis was studied during re-initiation of growth from the stationary phase and not in mid-exponential phase as in the present study. When [ $\left.{ }^{32} \mathrm{P}\right]$ orthophosphoric acid was used as a precursor, incorporation was linear for $6 \mathrm{~min}$ (Fig. $1 \mathrm{~b}$ ) and the rate of synthesis of PS was highest, as observed with $\left[{ }^{14} \mathrm{C}\right]$ acetate. Among the other phospholipids, PI was synthesized at a higher rate than PE and PC. Our results of lipid biosynthesis confirm the lipid composition of C. albicans (Table 1) and that PS was the major phospholipid while other phospholipids have lower, relatively similar, concentrations.

While studies with $\left[{ }^{14} \mathrm{C}\right]$ acetate and $\left[{ }^{32} \mathrm{P}\right]$ orthophosphoric acid as precursors give a generalized view of phospholipid biosynthesis, incorporation of various specific bases (choline, ethanolamine and serine) into lipid fractions was also examined to define the contribution of these bases to total PL biosynthesis. Of these three bases, maxium incorporation into total lipids and phospholipids was observed with $\left[{ }^{14} \mathrm{C}\right]$ choline chloride followed by $\left[{ }^{3} \mathrm{H}\right]$ ethanolamine and $\left[{ }^{14} \mathrm{C}\right]$ serine; incorporation of all three bases increased for $9 \mathrm{~min}$ (data not shown).

Incorporation of $\left[{ }^{14} \mathrm{C}\right]$ choline into individual phospholipids in 9 min (Table 2) showed around $87 \%$ incorporation into lysophosphatidylcholine (LPC) plus $\mathrm{PC}$ and negligible incorporation into the others. Direct incorporation of $\left[{ }^{14} \mathrm{C}\right]$ choline into $\mathrm{PC}$ indicated the cytidine pathway for PC synthesis, which has been shown in other fungi (Kasinathan \& Khuller, 1983).

When $\left[{ }^{3} \mathrm{H}\right]$ ethanolamine was used as a precursor, maximum radioactivity $(62 \%)$ was again observed in choline-containing lipids and only about $6 \%$ was detected in PE, while the rest was distributed in other phospholipids. Even after only $3 \mathrm{~min}, 54 \%$ of the radioactivity was present in the PC plus LPC fraction, whereas there was no difference in incorporation of radioactivity between 3 and $9 \mathrm{~min}$ into the $\mathrm{PE}$ fraction (data not shown). The rapidity of incorporation of labelled ethanolamine into PC and LPC suggests that PE is not the only substrate for methylation but that ethanolamine, phosphorylethanolamine and CDP-ethanolamine are also methylated using $S$-adenosylmethionine as the methyl donor, as suggested in mammalian
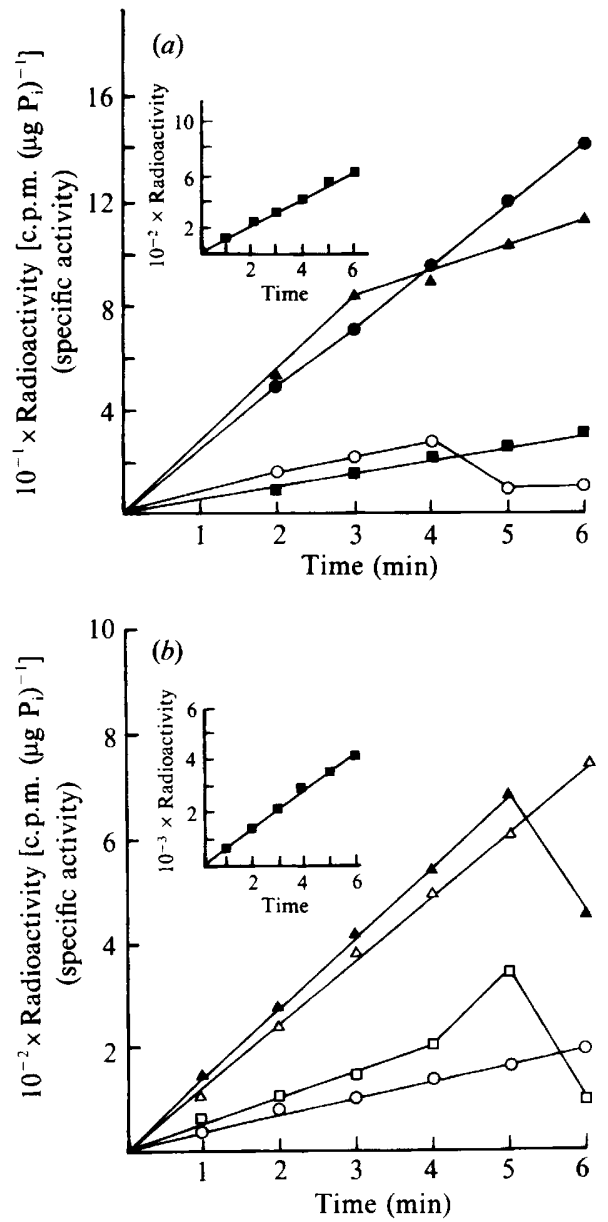

Fig. 1. (a) Incorporation of $\left[{ }^{14} \mathrm{C}\right]$ acetate into phospholipids of $C$. albicans 3153 . The inset shows incorporation of $\left[{ }^{14} \mathrm{C}\right]$ acetate into total lipids [c.p.m. (mg total lipid) ${ }^{-1}$ ]. (b) Incorporation of [ ${ }^{32}$ P]orthophosphoric acid into individual phospholipids. The inset shows incorporation of [ $\left.{ }^{32} \mathrm{P}\right]$ orthophosphoric acid into total phospholipids (units as in main figure). $\bullet$, Total phospholipids; $\triangle$, PS; $\triangle$, PI; $\square, \mathrm{PC} ; \mathrm{O}, \mathrm{PE}$.

systems (Salerno \& Beler, 1973). However, this pathway needs further confirmation. Increased uptake into LPC as compared to other phospholipids may be due to degradation of PC to LPC by phospholipase A, which has been identified in this fungus (unpublished observations).

Studies with $\left[{ }^{14} \mathrm{C}\right]$ serine yielded results similar to the ethanolamine incorporation experiments. The incorporation into PS decreased from $36.9 \%$ after $3 \mathrm{~min}$ of pulse to $11.0 \%$ after $9 \mathrm{~min}$ while it increased in cholinecontaining lipids from $48.0 \%$ to $56.6 \%$, indicating that PS is converted to PC. These results suggest that PS is decarboxylated by PS decarboxylase and then subsequently methylated to $\mathrm{PC}$ by methyltransferases. Earlier workers obtained similar results when they studied incorporation of $\left[{ }^{14} \mathrm{C}\right]$ serine in Saccharomyces cerevisiae in vivo and in vitro (Nikawa \& Yamashita, 1983; Steiner \& Lester, 1972). 
Table 2. Incorporation of nitrogenous bases into various lipid fractions of C. albicans 3153

\begin{tabular}{|c|c|c|c|}
\hline Fraction & {$\left[{ }^{14} \mathrm{C}\right]$ Choline chloride } & {$\left[{ }^{3} \mathrm{H}\right]$ Ethanolamine } & {$\left[{ }^{14} \mathrm{C}\right]$ Serine } \\
\hline $\begin{array}{l}\text { Total lipids } \\
{\left[\mu \mathrm{mol}(\mathrm{mg} \text { total lipid })^{-1}\right]}\end{array}$ & $1 \cdot 26$ & 0.020 & 0.010 \\
\hline $\begin{array}{l}\text { Total phospholipids } \\
\text { [nmol (mg lipid-P) }\end{array}$ & 0.22 & $0 \cdot 052$ & 0.002 \\
\hline \multicolumn{4}{|l|}{$\begin{array}{l}\text { Individual phospholipids } \\
\text { (percentage incorporation)* }\end{array}$} \\
\hline LPC & $2 \cdot 00$ & $23 \cdot 86$ & $14 \cdot 15$ \\
\hline PS & 3.00 & 15.08 & 10.97 \\
\hline PI & 2.84 & 11.79 & $10 \cdot 06$ \\
\hline PC & $85 \cdot 16$ & $38 \cdot 40$ & 42.43 \\
\hline PE & 3.53 & 6.44 & $12 \cdot 37$ \\
\hline $\mathrm{CL}$ & 3.65 & 4.88 & $9 \cdot 30$ \\
\hline
\end{tabular}

* Values are means of two different batches.

\section{Concluding remarks}

This study has demonstrated that in C. albicans 3153 , microsomes are the major reservoir of phospholipids represented by PS, PC, PE and PI. Choline was found to be a specific precursor for $\mathrm{PC}$, whereas serine and ethanolamine could be used for the biosynthesis of other phospholipids.

This study was financed, in part, by a grant from Council of Scientific and Industrial Research, New Delhi.

\section{References}

Ballman, G. E. \& Chaffin, W. L. (1979), Lipid synthesis during reinitiation of growth from stationary phase cultures of Candida albicans. Mycopathologia 67, 39-43.

BLIGH, E. G. \& DYER, W. J. (1959). A rapid method of total lipid extraction and purification. Canadian Journal of Biochemistry and Physiology 37, 911-917.

Chavant, L., Dargent, R., Rami, J. \& Montant, C. (1980). Characterization of subcellular fractions, mitochondria and microsomes in two filamentous fungi. Biology of the Cell 37, 299-303.

Folch, J., Lees, M. \& Stanley, G. H. S. (1957). A simple method for the isolation and purification of total lipids from animal tissues. Journal of Biological Chemistry 226, 497-509.

Fryberg, M., Oehlschlager, A. C. \& Unrau, A. M. (1975). Sterol biosynthesis in antibiotic sensitive and resistant Candida. Archives of Biochemistry and Biophysics 173, 171-177.

Ghannoum, M. A., Janini, G., Khamis, L. \& Radwan, S. S. (1986). Dimorphism associated variations in the lipid composition of Candida albicans. Journal of General Microbiology 132, 2367-2375.

Henry, S. A., Grenberg, M. L., LetTS, U. A., Schiker, B., Klig, L. \& ATKINSON, V. D. (1981). Current developments in yeast research. In Advances in Biotechnology, pp. 311-316. Edited by G. G. Stewart \& I. Russell. Oxford: Pergamon Press.

Hitchcock, C. A., Barrett-Bee, K. J. \& Russell, N. J. (1986). The lipid composition of azole-sensitive and azole-resistant strains of Candida albicans. Journal of General Microbiology 132, 2421-2431.

Kaneko, H., Hosdharia, M., Tabaka, M. \& ITOH, T. (1976). Lipid composition of 30 species of yeast. Lipids 11, 837-844.
Kasinathan, C. \& Khuller, G. K. (1983). Biosynthesis of major phospholipids of Microsporum gypseum. Biochimica et Biophysica Acta 752, 187-190.

Khuller, G. K., Chopra, A., Bansal, V. S., Masih, R. (1981). Lipids of dermatophytes. Lipids 16, 20-22.

Kilburn, J. O., Takayama, K., Armstrong, E. L. \& Grenberg, J. (1981). Effect of ethambutol on phospholipid metabolism in Mycobacterium smegmatis. Antimicrobial Agents and Chemotherapy 19, 346-348

Malkhas'ian, S. S., Nechaev, A. P., Gaurilova, N. N., Zotova, E. E. \& DORONINA, O. D. (1982). The group of fatty acid composition of the lipids in yeasts of genus Candida. Prikladnaya Biokhimiya $i$ Mikrobiologiya 18, 621-629 (in Russian).

MARINETTI, G. H. (1962). Chromatographic separation, identification and analysis of phosphatides. Journal of Lipid Research 3, 1-20.

MARRIOTT, M. S. (1975). Isolation and chemical characterization of plasma membranes from the yeast and mycelial forms of Candida albicans. Journal of General Microbiology 89, 345-352.

Nikawa, J. \& Yamashita, S. (1983). 2-Hydroxyethylhydrazine as a potent inhibitor of phospholipid methylation in yeast. Biochimica et Biophysica Acta 751, 201-209.

Pierce, A. M., Pierce, H. D., JR, Unrau, A. M. \& Oehlschlager, A. C. (1978). Lipid composition and polyene antibiotic resistance of Candida albicans mutants. Canadian Journal of Biochemistry 56, 135142.

Salerno, D. M. \& Beler, D. A. (1973). The biosynthesis of phospholipids and their precursors in rat liver involving de novo methylation and base exchange pathways, in vivo. Biochimica et Biophysica Acta 326, 325-338.

Singh, M., Jayakumar, A. \& Prasad, R. (1979). Lipid composition and polyene antibiotic sensitivity in isolates of Candida albicans. Microbios 24, 7-17.

STEINER, M. R. \& LESTER, R. L. (1972). In vitro studies of phospholipid biosynthesis in Saccharomyces cerevisiae. Biochimica et Biophysica Acta 260, 222-243.

WeETE, J. D. (1980). Fungal lipids. In Lipid Biochemistry of Fungi and Many Other Organisms. pp. 9-48. Edited by J. D. Weete. New York \& London: Plenum Press.

YamaGuCHI, H. (1977). Antagonistic action of lipid components of membranes from Candida albicans and various other lipids on two imidazole antimycotics, clotrimazole and miconazole. Antimicrobial Agents and Chemotherapy 12, 16-25.

Zlatkis, A., Zak, B. \& Boyles, A. J. (1953). A new method for the direct determination of serum cholesterol. Journal of Laboratory and Clinical Medicine 41, 486-492. 